\title{
Sampling cows to assess lying time for on-farm animal welfare assessment
}

\author{
E. Vasseur, ${ }^{\star 1,2}$ J. Rushen, ${ }^{*}$ D. B. Haley, $†$ and A. M. de Passillé ${ }^{\star}$ \\ ${ }^{*}$ Pacific Agri-Food Research Centre, Agriculture and Agri-Food Canada, Agassiz, British Columbia, Canada, V0M 1A0 \\ †Department of Population Medicine, University of Guelph, Guelph, Ontario, Canada, N1G 2W1
}

\begin{abstract}
The time that dairy cows spend lying down is an important measure of their welfare, and data loggers can be used to automatically monitor lying time on commercial farms. To determine how the number of days of sampling, parity, stage of lactation, and production level affect lying time, electronic data loggers were used to record lying time for $10 \mathrm{~d}$ consecutively, at 3 stages of lactation [early: when cows were at 10-40 $\mathrm{d}$ in milk (DIM), mid: 100-140 DIM, late: 200-240 DIM] of 96 Holstein cows in tiestalls (TS) and 127 in freestalls (FS). We calculated daily duration of lying, bout frequency, and mean bout duration. We observed complex interactions between parity and stage of lactation, which differed somewhat between tiestalls and freestalls. First-parity cows had higher bout frequency and shorter lying bouts than older cows but bout frequency decreased and mean bout duration increased as DIM increased. We found that individual cows were not consistent in time spent lying between early and mid lactation (Pearson coefficient, TS: $\mathrm{r}=0.1, \mathrm{FS}: \mathrm{r}=0.2$ ), whereas cows seemed to be more consistent in time spent lying between mid and late lactation (TS: $\mathrm{r}=$ 0.7 , FS: $\mathrm{r}=0.3$ ). For both TS and FS cows, daily milk production was significantly, but slightly negatively, correlated with lying time across the lactation (range, r: -0.2 to -0.4 ), whereas parity was slightly to moderately positively correlated with mean bout duration across the lactation (r: +0.2 to +0.6$)$ and negatively with bout frequency ( $\mathrm{r}:-0.2$ to -0.5 ). To estimate how the duration of the time sample affected the estimates of lying time subsets of data subsets consisting of 1 , $2,3,4,5,6,7,8$, and $9 \mathrm{~d}$ per cow were created, and the relationship between the overall mean (based on 10 d) and the mean of each subset was tested by regression. For both TS and FS, lying time based on $4 \mathrm{~d}$ of sampling provided good estimates of the average 10-d
\end{abstract}

\footnotetext{
Received November 22, 2011.

Accepted May 7, 2012.

${ }^{1}$ Corresponding author: vasseur.elsa@gmail.com

${ }^{2}$ Current address: Organic Dairy Research Center, Université de Guelph - Campus d'Alfred, Alfred, Ontario, Canada, K0B 1A0.
}

estimate (90\% of accuracy). Automated monitoring of lying time has potential as a measure of dairy cow welfare on commercial farms but cows differ greatly in lying time. To obtain a representative measure for the herd, it is necessary to sample cows based on their parity and stage of lactation but probably not milk production level.

Key words: lying time, dairy cow, tiestall, freestall

\section{INTRODUCTION}

The measures for assessing animal welfare are conventionally divided into input-based measures, which describe the environment of the animal or the management practices used, and outcome- or animal-based measures, which describe the actual state of the animal (Rushen et al., 2008; Knierim and Winckler, 2009). One advantage of outcome-based measures is that they can be used to compare the welfare of animals housed in very different types of housing systems. However, outcome-based measures can be time consuming to record and it is often difficult to ensure inter-assessor reliability (Rushen et al., 2011). Therefore, the use of automated methods to record outcome-based measures of welfare would be a great asset.

Lying time has been used as a measure of dairy cow welfare and automated monitoring of lying time has been used to assess cow welfare on commercial farms (Ito et al., 2009). The average time that cows lie down each day varies, depending on, for example, aspects of stall design. Uncomfortable conditions (hard floors, wet bedding, or small stalls) reduce cow lying time (e.g., Haley et al., 2000) and reduced lying time has been associated with higher incidence of injuries (e.g., Rushen et al., 2007). Stall design and its association with injuries is not the only factor affecting lying time. Research suggests that lameness is preceded by a period of reduced lying time (Chapinal et al., 2009; Proudfoot et al., 2010), and lame cows subsequently lay down more (Chapinal et al., 2009, 2010a,b). Finally, behavioral and physiological changes in cows prevented from lying down suggest that prevention of lying is stressful (Munksgaard and Løvendahl, 1993; Munksgaard and Simonsen, 1996; Fisher et al., 2002). Therefore, auto- 
mated measurement of lying time has a lot of potential as an outcome measure to assess welfare on commercial dairies.

Although the total daily duration of time spent lying is the measure most commonly used, measures of bout frequency and bout duration may also be informative. Haley et al. (2001) showed that cows in tiestalls with hard floors lay down less frequently but in longer bouts than cows in stalls with softer floors. This may reflect discomfort experienced by the cows during the process of standing up and lying down.

Ito et al. (2009)'s study of Canadian dairy farms showed that the variation between farms in the average time spent lying down each day was small, but that the variation between cows was much larger. Thus, to effectively use lying time as a herd-level measure of dairy cow welfare in commercial farm situations, we need to obtain a representative measure of lying time of the herd and we need to know how to sample cows with respect to individual differences and other factors that may influence lying time such as parity (Singh et al., 1993), stage of lactation (Olmos et al., 2009), and milk production level (Fregonesi and Leaver, 2002). The duration of the sampling period is another important aspect to consider when measuring average lying time in a herd. Ito et al. (2009) suggested that a sampling period of $4 \mathrm{~d}$ is sufficient to obtain a representative estimate of lying time in large freestall herds, and whether this is the same for tiestalls needs to be confirmed.

In this study, we did the analyses from the perspective of an auditor or animal welfare assessor needing to choose a sample of cows from which to take measures of lying time. Therefore, to estimate if these factors need to be taken in account when sampling cows, the effect of number of days sampled, parity, stage of lactation, and milk production level on lying time of dairy cows in tiestall (TS) and freestall (FS) housing was evaluated. Three variables of lying behavior were examined: daily duration of lying, bout frequency, and mean bout duration. In addition, we tested if the differences between individual cows in lying time were constant over the lactation.

\section{MATERIALS AND METHODS}

\section{Animals and Housing}

Tiestall Cows. We used 96 lactating Holstein cows [parity range 1-6 with $48 \%$ of cows in parity 1 ; multiparous cows 305-d mature-equivalent milk yield (305ME) mean $\pm \mathrm{SD}=11,452 \mathrm{~kg} \pm 1,072 \mathrm{~kg}]$ from the University of Guelph's dairy research center (Elora, ON, Canada) housed in tiestalls (bed: $1.88 \mathrm{~m}$ long $\times 1.15 \mathrm{~m}$ wide; chain length $0.53-0.56 \mathrm{~m}$ ) with a stall base of geotextile mattress (Pasture Mat, Promat Inc., Woodstock, ON, Canada) covered with a layer of chopped straw. The TS cows were fed a TMR diet 3 times daily, at approximately 0530, 1300, and $1600 \mathrm{~h}$, that was formulated to meet requirements for lactating dairy cows (NRC, 2001). Water was freely available from water bowls (1 for 2 neighboring cows). Cows were milked twice daily in a parlor at approximately 0430 and $1445 \mathrm{~h}$.

Freestall Cows. We used 127 lactating Holstein cows (parity range 1-9 with $34 \%$ of cows in parity 1; multiparous cows $305 \mathrm{ME}$ yield mean $\pm \mathrm{SD}=11,496 \mathrm{~kg}$ $\pm 1,690 \mathrm{~kg}$ ) from the University of British Columbia's dairy research center (Agassiz, BC, Canada) housed in sand-bedded freestalls $(2.4 \mathrm{~m}$ long $\times 1.18 \mathrm{~m}$ wide $\times 0.40$ $\mathrm{m}$ deep, at least 1 per cow, in pens ranging from 12 to 48 cows). The routine management of the cows involved relocating the cows in new pens on a regular basis. First- and higher-parity cows were mixed together in pens. The FS cows were fed a TMR diet twice daily, at 0700 and $1600 \mathrm{~h}$, that was formulated to meet requirements for lactating dairy cows (NRC, 2001). Water was freely available from self-filling troughs. Lactating cows were milked twice daily in a parlor at approximately 0800 and $1700 \mathrm{~h}$.

\section{Data Collection}

Data collection took place over a year and was continuous (no clearly defined periods). Measures of lying time were collected over consecutive $10-\mathrm{d}$ periods in 3 stages of lactation: early lactation (when animals were between 10 and 40 DIM), mid lactation (between 100 and 140 DIM), and late lactation (between 200 and 240 DIM). At each stage, parity and daily milk production (based on 10-d average) were recorded (Table 1). Cows with identified health issues for the period from $10 \mathrm{~d}$ before until $10 \mathrm{~d}$ after data collection, as well as cows hoof-trimmed during the $10 \mathrm{~d}$ of data collection, were removed from the data set.

\section{Lying Time}

Electronic data loggers were used to record lying behavior of the focal cows (tiestalls: Afimilk Pedometer, S.A.E. Afikim, Kibbutz Afikim, Israel; freestalls: Tinytag Plus, Gemini Dataloggers Ltd., Chichester, UK; Hobo Pendant G Aceleration Data Loggers, Onset Computer Corp., Pocasset, MA). The 3 loggers were previously validated for recording standing and lying behavior in dairy cows, and the 2 types used for FS cows have been tested against each other (O'Driscoll et al., 2008; Ito et al., 2009; Higginson et al., 2010). For each focal cow, only one type of data logger was used. The data logger was placed in a fabric pouch and 
Table 1. Number of cows and daily milk production (mean $\pm \mathrm{SD}, \mathrm{kg}$ of milk/d) at 3 stages of lactation (early, mid, and late) for tiestall- and freestall-housed cows

\begin{tabular}{lccc}
\hline & \multicolumn{3}{c}{ Lactation stage } \\
\cline { 2 - 4 } Group & Early & Mid & Late \\
\hline Tiestall & & & 45 \\
$\quad$ No. of cows & 82 & $37.9 \pm 6.3$ & $32.0 \pm 6.3$ \\
$\quad$ Daily milk production & $39.2 \pm 7.4$ & 91 & 105 \\
Freestall & 73 & $39.2 \pm 8.8$ & $31.6 \pm 7.3$ \\
$\quad$ No. of cows & $41.7 \pm 10.4$ & & \\
Daily milk production & &
\end{tabular}

attached to a hind leg of each FS cow using Vet-Wrap (CoFolex, Andover Coated Products Inc., Salisbury, MA) or directly attached to a hind leg of each TS cow using a Velcro strap (Velcro USA Inc., Manchester, $\mathrm{NH})$. The data logger was programmed to record position of the cow (lying or standing) at 1-min intervals for $10 \mathrm{~d}$. Data were downloaded twice a day at milking for TS cows or downloaded once the data loggers were removed after each 10-d period of data collection for FS cows. Durations of individual lying bouts were computed using Excel macros (Microsoft Corp., Redmond, WA) for each 10-d period.

\section{Statistical Analysis}

All statistical analyses were performed using SAS software (version 9.2; SAS Institute Inc., Cary, NC). Analyses were done separately for TS and FS cows. We did the analyses from the perspective of a possible auditor or animal welfare assessor needing to choose a sample of cows from which to take measures of lying time. Information on the parity and stage of lactation would likely be available for most or all farms and could be used to select cows in advance. Therefore, we did our main analyses using these variables. Measures of milk production would not be available from many farms or could only be obtained with difficulty (and milk production from the previous lactation would not be available for primiparous cows). Therefore, we did not include this in our initial model, as inclusion may have reduced the effect of parity and stage of lactation. We did secondary regressions to see if including milk production would help in selecting cows on farms where this information was available.

To determine how stage of lactation affected the estimates of lying time, only focal cows followed at 2 or 3 stages of lactation during the same lactation were used ( $\mathrm{n}=83$ TS cows; $\mathrm{n}=112$ FS cows). The overall averages based on $10 \mathrm{~d}$ (or a minimum of $7 \mathrm{~d}$ when there were missing values) were calculated for daily duration of lying time $(\mathrm{h} / \mathrm{d})$, bout frequency (bout/d), and mean bout duration (min/bout) for each cow.
Compliance with the assumptions of normality and homogeneity of variances were checked using the UNIVARIATE procedure. Natural logarithmic transformation was applied to bout frequency and mean bout duration to normalize these distributions. We checked for extreme outliers (3 times the interquartile range outside of the interquartile limits) but none were removed from analyses. The differences in lying time between the 3 stages of lactation were tested using a generalized linear mixed model (GLIMMIX) with cow as random effect and stage of lactation as factor. Parity was forced into all models to look at the interaction of stage of lactation and parity on lying time. Parity was classified as primiparous or multiparous. Least squares means of each lying variable were back-transformed where applicable.

Pearson coefficients of correlation (using procedure CORR) across cows between the different stages of lactation within the same parity were calculated to verify if the individual differences in lying time were stable across the lactation (no. of cows early to mid and mid to late: $\mathrm{n}=59$ and 27 cows, respectively, for TS, and $\mathrm{n}$ $=46$ and 64 for FS).

To test the effect of parity, daily milk production, and 305ME yield on lying time at each stage of lactation (early, mid, and late), regressions (using the procedure REG, forward stepwise regression selection model, level of significance to enter into the model was $P<$ $0.05)$ were calculated separately. Regressions were run with the 3 variables on multiparous cows only (no. of cows for early, mid, and late: $\mathrm{n}=26,33$, and 20 cows, respectively, for TS, and $\mathrm{n}=32,62$, and 54 for FS) to test the effect of 305ME yield; then, regressions were run only with the 2 variables parity and daily milk production on all cows (no. of cows for early, mid, and late: $\mathrm{n}=68,73$, and 33 cows, respectively, for TS, and $\mathrm{n}=50,90$, and 83 for FS). Parity was classified as 1 , 2,3 , or $\geq 4$.

To estimate how the duration of the time sample affected the estimates of lying time, focal cows with complete data for $10 \mathrm{~d}$ at 1,2 or 3 stages of lactation (TS: $\mathrm{n}=170$; FS: $\mathrm{n}=234$ ) were used to create subsets 
of data consisting of $1 \mathrm{~d}, 2 \mathrm{~d}, 3 \mathrm{~d}, 4 \mathrm{~d}, 5 \mathrm{~d}, 6 \mathrm{~d}, 7 \mathrm{~d}$, $8 \mathrm{~d}, 9 \mathrm{~d}$ per cow by using simple random sampling in PROC SURVEYSELECT with strata specified as cow and stage of lactation. The procedure was repeated 10 times for each subset, and the relationship between the overall mean (based on $10 \mathrm{~d}$ ) and the mean of each subset was tested using a regression model (PROC REG). The $10 \mathrm{R}^{2}$ values resulting from the 10 repetitions of the procedure for each subset ( $1 \mathrm{~d}$ to $9 \mathrm{~d}$ ) were averaged to estimate a mean and standard deviation for each subset. Estimates were calculated for daily duration of lying, bout frequency, and mean bout duration.

\section{RESULTS}

\section{Effect of Stage of Lactation, Parity, and Milk Production on Lying Time}

Complex interactions existed between stage of lactation and parity, which differed somewhat between TS and FS (Table 2). In FS, we observed an effect of stage of lactation, with no interaction between stage and parity for daily duration of lying; the daily duration of lying increased with stage of lactation in primiparous and multiparous cows (Figure 1a). In first-parity cows, this increase in daily duration of lying with stage of lactation was associated with increased bout duration (Figure 1c) and decreased bout frequency (Figure 1b). However, these changes in bout frequency and duration were not as apparent in older cows.

In TS, we observed an interaction between parity and stage of lactation: the daily duration of lying increased regularly over the lactation in the primiparous cows but this increase was less regular in multiparous cows (Figure 1a). A reduced bout frequency (Figure 1b) and increased bout duration (Figure 1c) with increased stage of lactation was observed in primiparous and multiparous cows.
For both TS and FS cows, a nonsignificant correlation was found between early and mid lactation in daily lying duration, but bout frequency and mean bout duration were moderately to highly correlated (Table 3). However, moderate to high correlations were found between mid and late lactation for all 3 variables of lying time (Table 3).

From the regression models run with $305 \mathrm{ME}$ yield, we found that $305 \mathrm{ME}$ yield was positively associated only at mid lactation with mean duration of lying bout for FS cows $(\mathrm{r}=+0.3 ; P<0.05)$. From the regression models run with daily milk production, we found that daily milk production was negatively associated with daily duration of lying time in early lactation for FS cows, and in mid lactation for TS cows (Table 4). Daily milk production was negatively associated with bout frequency in mid lactation for TS cows and with bout duration in late lactation for FS cows (Table 4).

We found no simple effects of parity, even within stages of lactation. Parity was positively associated with lying time only during early lactation in TS but not FS (Table 4). Parity was negatively associated with bout frequency in early and mid lactation and positively associated with bout duration at all stages of lactation in both TS and FS (Table 4).

\section{Effect of Duration of the Time Sample on Lying Time}

We tested the relationships between average 10-d estimates of lying time and subsets of 1 to $9 \mathrm{~d}$ randomly sampled (Figure 2). For both TS and FS cows, subsets based on a 4-d sample provided good estimates of the average $10-\mathrm{d}$ estimate $\left(\mathrm{R}^{2}>0.9, P<0.001\right)$ for all 3 variables of lying time. A single-day sampling provided estimates with 63 to 80,69 to 81 , and 60 to $72 \%$ of accuracy compared with the overall average based on 10 $\mathrm{d}$ for daily duration of lying, bout frequency, and mean bout duration, respectively.

Table 2. Test of the effect of stage of lactation (early, mid, and late lactation) and parity (2 classes: primiparous and multiparous) on daily duration of lying, bout frequency, and mean bout duration for tiestall and freestall cows

\begin{tabular}{|c|c|c|c|c|c|c|c|}
\hline Item & df & \multicolumn{2}{|c|}{ Stage of lactation } & \multicolumn{2}{|c|}{ Parity } & \multicolumn{2}{|c|}{ Stage $\times$ parity } \\
\hline Bout frequency (bout/d) & & 8.7 & $* * *$ & 16.0 & $* * *$ & 0.4 & NS \\
\hline Mean bout duration (min/bout) & & 47.3 & $* * *$ & 22.0 & $* * *$ & 3.3 & $*$ \\
\hline \multicolumn{8}{|l|}{ Freestall } \\
\hline Mean bout duration (min/bout) & & 25.0 & *** & 20.1 & $* * *$ & 14.9 & $* * *$ \\
\hline
\end{tabular}

${ }^{1}$ Degrees of freedom and type I tests of fixed effects (GLIMMIX procedure, F-value and $P>\mathrm{F}$ ) of stage of lactation, parity, and stage of lactation $\times$ parity interaction are shown for all 3 variables of lying time.

$\mathrm{NS}=P>0.1 ; \dagger P<0.1$ (tendency); ${ }^{*} P<0.05 ; * * * P<0.001$. 
TS

(a)

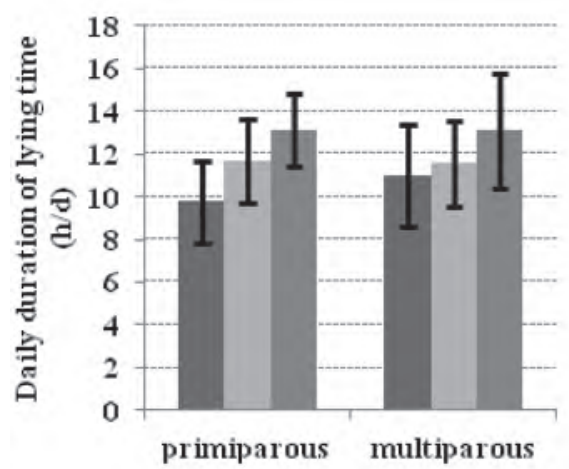

(b)

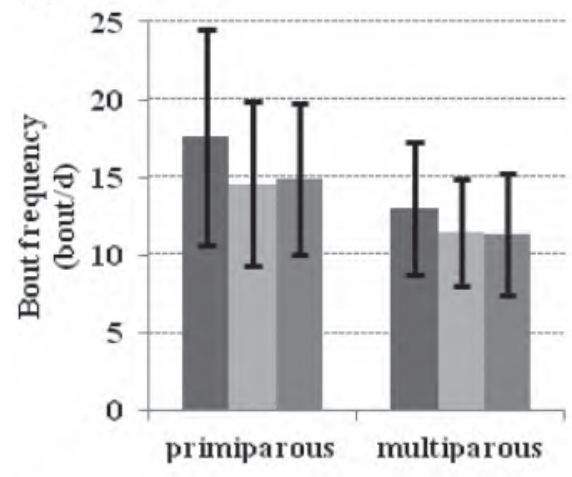

(c)

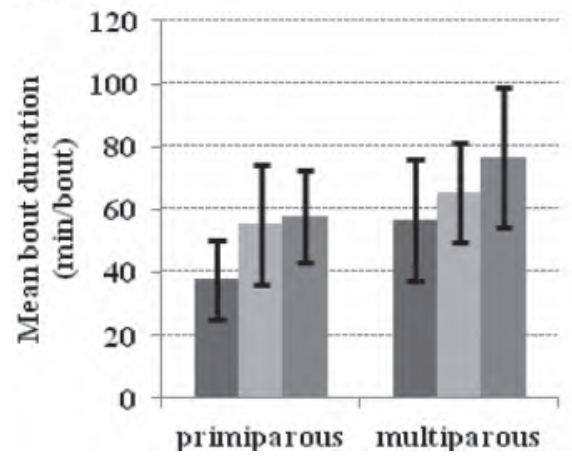

EEARLY

MIID

nLATE
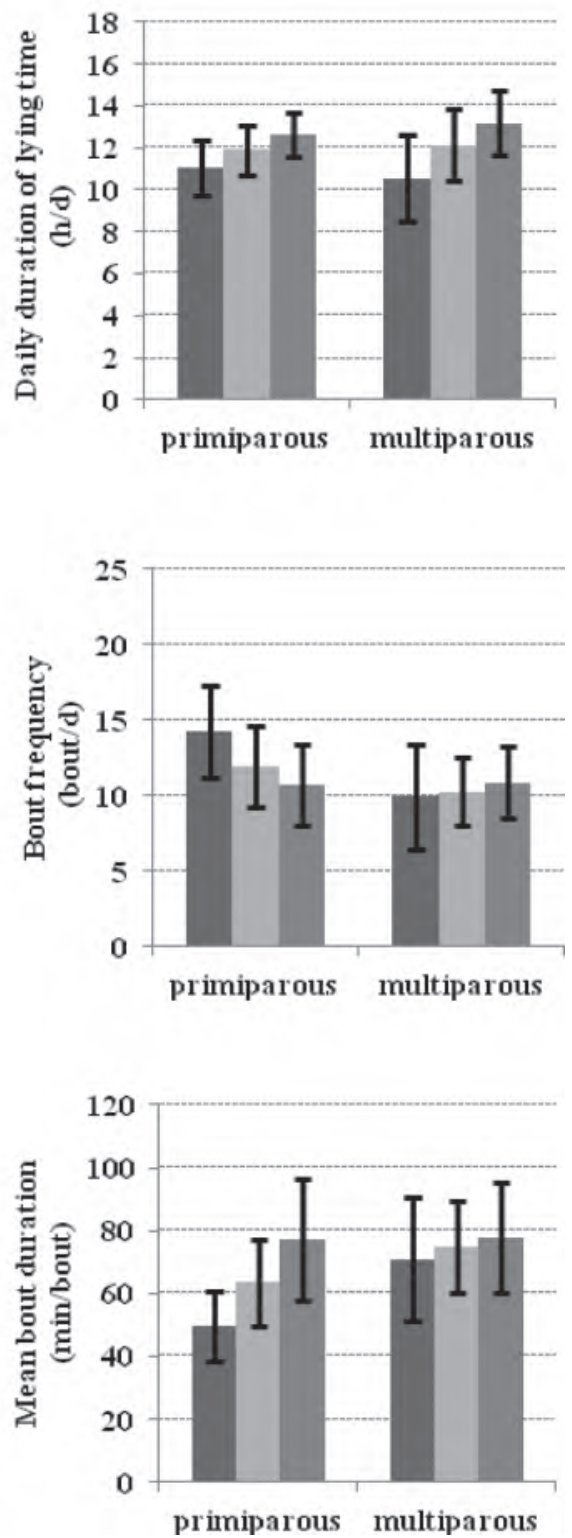

Figure 1. Mean ( $\pm \mathrm{SD}$ ) daily duration of lying time (a; h/d), bout frequency (b; bout/d), and mean bout duration (c; min/bout) for primiparous and multiparous tiestall (TS) and freestall (FS) cows over the lactation (early, mid, and late lactation). For bout frequency and mean bout duration, back-transformed means with natural log-transformation were applied to the variable.

\section{DISCUSSION}

\section{Effect of Stage of Lactation, Parity, and Milk Production on Lying Time}

Average daily lying time measured in our study correspond with values reported in previous studies in ti- estall housing (Rushen et al., 2007; Tucker et al., 2009) and freestall housing (Fregonesi and Leaver, 2002; Fregonesi et al., 2007).

We found complex effects of stage of lactation and parity on lying time, which differed somewhat between FS and TS. In both systems, the daily duration of time spent lying down increased with increased DIM 
Table 3. Correlation (r: Pearson coefficient and $P$-value) across tiestall and freestall cows between different stages of lactation for daily duration of lying, bout frequency, and mean bout duration

\begin{tabular}{|c|c|c|c|c|c|c|}
\hline \multirow[b]{2}{*}{ Group } & \multicolumn{3}{|c|}{$\begin{array}{c}\text { Between early } \\
\text { and mid lactation }\end{array}$} & \multicolumn{3}{|c|}{$\begin{array}{c}\text { Between mid } \\
\text { and late lactation }\end{array}$} \\
\hline & $\mathrm{n}^{1}$ & $\mathrm{r}$ & $P$-value & $\mathrm{n}$ & $\mathrm{r}$ & $P$-value \\
\hline \multicolumn{7}{|l|}{ Tiestall } \\
\hline Daily duration of lying $(\mathrm{h} / \mathrm{d})$ & 59 & 0.1 & NS & 27 & 0.7 & $* * *$ \\
\hline Bout frequency (bout/d) & & 0.6 & $* * *$ & & 0.5 & $* * *$ \\
\hline Mean bout duration ( $\mathrm{min} /$ bout) & & 0.7 & $* * *$ & & 0.6 & $* * *$ \\
\hline \multicolumn{7}{|l|}{ Freestall } \\
\hline Daily duration of lying $(\mathrm{h} / \mathrm{d})$ & 46 & 0.2 & NS & 64 & 0.3 & ** \\
\hline Bout frequency (bout/d) & & 0.4 & ** & & 0.6 & $* * *$ \\
\hline Mean bout duration (min/bout) & & 0.3 & * & & 0.4 & ** \\
\hline
\end{tabular}

in first-parity cows. This was due to increased bout duration but decreased bout frequency, which suggests that it may be easier for primiparous cows in early lactation to get up and lie down. The effect of increasing DIM on daily duration of lying also occurred in later parities in cows in TS but was not significant in older cows in FS. Previous studies showed an increase in lying time as DIM increased due to an increase in mean bout duration (Nielsen et al., 2000; Chaplin and Munksgaard, 2001; Olmos et al., 2009). However, other research showed that the increase in daily duration of lying as DIM increased may be due to the increase in number of bouts rather than an increase in bout duration (Endres and Barberg, 2007), which is the opposite of what we found. Our results show that the effect of DIM on lying bout frequency and bout duration varied according to parity, so differences between studies may reflect differences in the ages of the cows studied. It is plausible that cow discomfort while lying (due to added pressure on their distended udder) is higher in early lactation. For this reason, cows spend less time lying down in early lactation, whereas lying time increases as udder distension decreases with progressing DIM. For example, Gleeson et al. (2007) reported the highest udder firmness scores in the first 8 wk following calving, with a decrease thereafter. However, another study showed no increase of udder distension as lactation progressed during the first $12 \mathrm{wk}$ of lactation (O'Driscoll et

Table 4. Selection by stepwise forward regression (r: coefficient of correlation) of the significantly influential variables (parity, daily milk production) affecting lying time (daily duration of lying time, bout frequency, and mean bout duration) at 3 stages of lactation for tiestall and freestall cows

\begin{tabular}{|c|c|c|c|c|c|c|c|c|c|}
\hline Group & \multicolumn{3}{|c|}{ Early } & \multicolumn{3}{|c|}{ Mid } & \multicolumn{3}{|c|}{ Late } \\
\hline \multicolumn{10}{|l|}{ Tiestall } \\
\hline Bout frequency (bout/d) & & Parity & $-0.5^{* * *}$ & & $\begin{array}{l}\text { Daily milk } \\
\text { production }\end{array}$ & $-0.4^{* * *}$ & & - & - \\
\hline \multicolumn{10}{|l|}{ Freestall } \\
\hline Daily duration of lying $(\mathrm{h} / \mathrm{d})$ & 50 & $\begin{array}{l}\text { Daily milk } \\
\text { production }\end{array}$ & $-0.3^{*}$ & 90 & - & - & 83 & - & - \\
\hline Bout frequency (bout/d) & & Parity & $-0.5^{* * *}$ & & Parity & $-0.2^{*}$ & & - & - \\
\hline Mean bout duration (min/bout) & & Parity & $+0.5^{* * *}$ & & Parity & $+0.2^{*}$ & & $\begin{array}{l}\text { Daily milk } \\
\text { production }\end{array}$ & \\
\hline & & & & & & & & Parity & $+0.3^{* 4}$ \\
\hline
\end{tabular}

${ }^{1} \mathrm{n}=$ number of cows.

${ }^{2}$ Significance level entry into the model was $P<0.05$.

${ }^{3}$ No variable reached the level of significance.

${ }^{4} \mathrm{r}$ value issued from cumulative $\mathrm{R}^{2}$ and reflects the amount of variation described by adding the significant variable to the model.

${ }^{*} P<0.05 ;{ }^{* *} P<0.01 ;{ }^{* * *} P<0.001$. 
(a)

TS

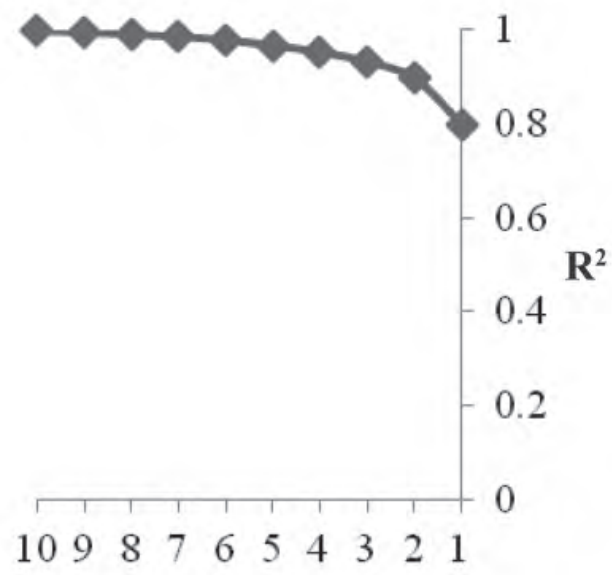

(b)

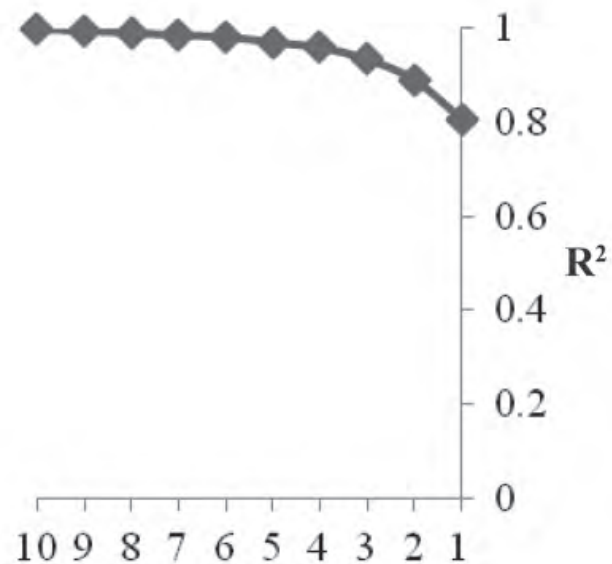

(c)

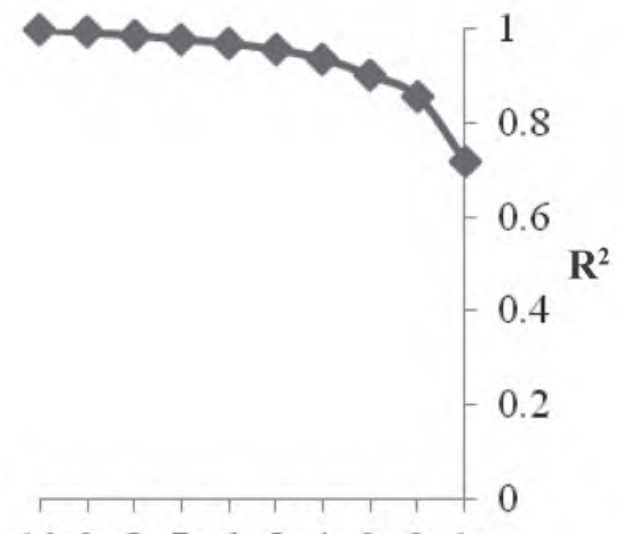

$\begin{array}{llllllllll}10 & 9 & 8 & 7 & 6 & 5 & 4 & 3 & 2 & 1\end{array}$

Days
FS

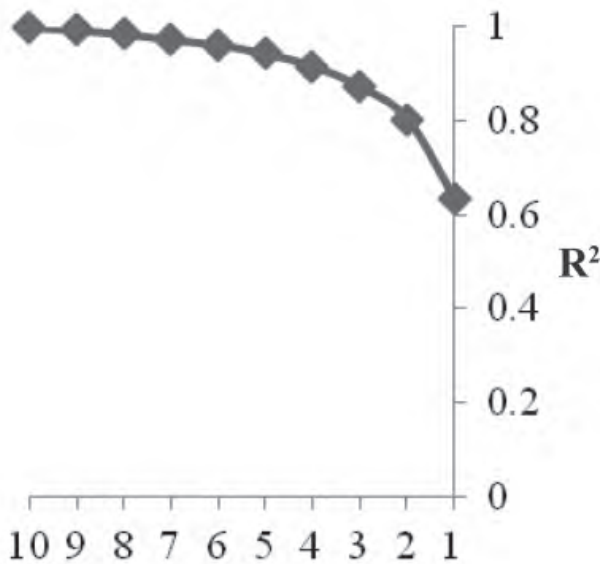

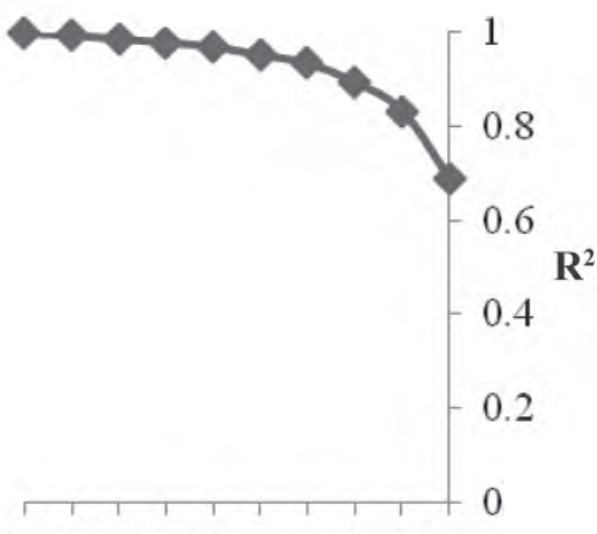

$\begin{array}{llllllllll}10 & 9 & 8 & 7 & 6 & 5 & 4 & 3 & 2 & 1\end{array}$

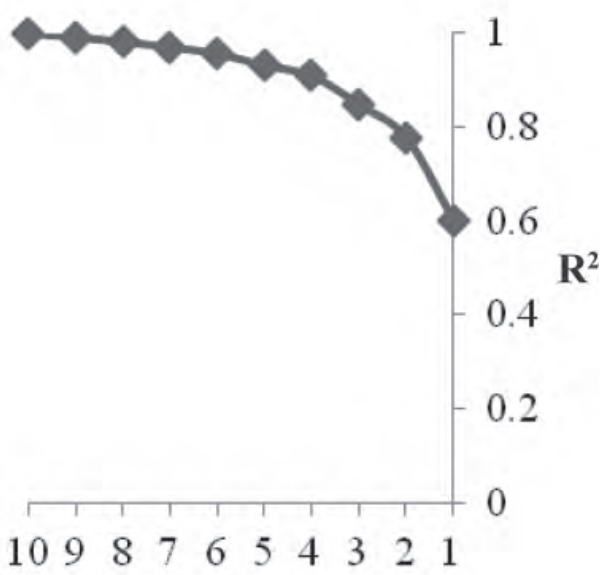

Days

Figure 2. Relationship $\left(\mathrm{R}^{2}\right)$ between average 10-d daily duration of lying time (a), bout frequency (b), and mean bout duration (c), and estimates derived from $9,8,7,6,5,4,3,2$, or $1 \mathrm{~d}$ randomly sampled for each tiestall (TS) and freestall (FS) cow (TS: $\mathrm{n}=170 ; \mathrm{FS}: \mathrm{n}=234)$. The standard deviations across the 10 random sampling events were too small to be visible. 
al., 2011). In general, however, our results show that it is difficult to draw simple conclusions about the effect of stage of lactation on lying time in cows.

More importantly, the demand for food, and hence time spent feeding, is higher in early compared with late lactation, which should reduce the time available for lying (Jensen et al., 2005). However, effect of stage of lactation on feeding patterns is not consistent through different studies. In freestall-housed cows, DeVries et al. (2003) showed an increase in feeding time of cows from early to peak lactation, whereas no change in feeding behaviors observed over the early part of lactation were found in cows housed in tiestalls (DeVries et al., 2009). Interestingly, the extra $2 \mathrm{~h}$ per day spent feeding by early lactation cows reported by DeVries et al. (2003) corresponds to the 2 to $3 \mathrm{~h}$ per day less time spent lying down that we found for primiparous cows in our study.

We tested whether differences between cows in lying time were consistent over the lactation to understand how much of the variation in lying time in a herd is due to stable individual differences. We found that individual cows are not consistent in time spent lying between early and mid lactation (i.e., cows that lie less in early lactation are not the same cows that lie less in mid lactation), whereas cows seem to be more consistent in time spent lying between mid and late lactation. Many differences occur in cows between d 10 and 40 and d 100 and 140 of lactation, such as the occurrence of estrus or the beginning of pregnancy, which may affect lying time. Furthermore, some of the differences may reflect subclinical postpartum illness; even if we removed identified sick or lame cows from our sample, some sickness signs of postpartum diseases (e.g., metritis) are more difficult to detect and can go unnoticed until the disease is in its clinical stage (von Keyserlingk et al., 2011). As an example, approximately $30 \%$ of the cows of the freestall barn studied were diagnosed with subclinical endometritis in a previous study (Wittrock et al., 2011).

We tested the effect of parity and milk production on lying time to estimate if parity needs to be taken into account when measuring lying time in a herd. Usually, the effects of parity interacted with the effects of stage of lactation, as described above. Within stages of lactation, parity did not consistently affect the daily duration of lying, but the frequency of lying bouts was generally higher and the duration of lying bouts was shorter for first-parity cows compared with older cows. This may reflect either a greater ease in standing up and lying down or a more disrupted rest patterns for younger cows. Similarly, shorter lying times in first-lactation cows have been shown by Singh et al. (1993). In freestall cows, the disruption in lying may be explained by first-lactation cows having low ranking positions within the group and therefore being displaced by older and more dominant cows. In addition, they are experiencing and adapting to an unfamiliar environment and routine (e.g., milking).

Our results for both TS and FS cows showed little effect of 305ME yield but several effects of daily milk production. However, these effects were weak and not consistent across the lactation period. Furthermore, the effects of milk production on lying time are not consistent with other studies. Fregonesi and Leaver (2001, 2002) and Norring et al. (2011) showed that high-yielding cows had shorter lying times than cows with a low milk yield; these differences increased with reduced number of stalls and were linked to an increase in agonistic interactions (Fregonesi and Leaver, 2002). However, another study showed no effect of milk production on lying time (Nielsen et al., 2000). Our results may reflect housing conditions that limited competition in both tiestall and freestall barns studied, which favored high- and low-yielding cows resting.

Based on this study, due to the weak association of milk production with lying time, it may not be necessary to account for milk production during sampling on commercial farms, which is also practical because it may be difficult to gather milk production data before the farm visit. However, it is important to consider sampling based on both stage of lactation and parity to obtain lying time estimates representative of the herd. Our results showed that lying time varies greatly between cows due to individual differences that may not be controlled when sampling (i.e., stage of lactation, parity). Thus, it is important to ensure that a large enough sample of cows is chosen to account for likely individual differences. Ito et al. (2009) suggested sampling 30 lactating cows to evaluate lying time of a herd of 44 or more freestall cows with $90 \%$ accuracy.

\section{Effect of Duration of the Time Sample on Lying Time}

When recording at 1-min intervals, a 4-d sampling period is necessary to estimate lying time with at least $90 \%$ accuracy compared with the overall average based on 10 consecutive days. By comparison, a single-day sampling provided estimates with 60 to $81 \%$ accuracy compared with the overall average based on $10 \mathrm{~d}$. To reach this level of accuracy, Ito et al. (2009)'s study, done on commercial freestall farms, needed only a $3-\mathrm{d}$ sampling period, whereas a single-day sampling provided estimates with approximately $75 \%$ accuracy; however, the overall average in that case was based on 5 d. However, a shorter sampling period may be more practical for farm auditing systems. Based on 
our results for TS and FS cows, we suggest that more research is needed for smaller farms to determine an accurate sample size before reducing the sample period to $1 \mathrm{~d}$, so as not significantly reduce the accuracy of lying time estimates.

\section{CONCLUSIONS}

Automatic monitoring of lying time has potential as a herd-level measure of dairy cow welfare on commercial tiestall and freestall farms. However, cows differ greatly in lying time and it is necessary to sample cows based on their stage of lactation and parity, but probably not milk production level, to obtain a representative measure of the herd. Depending on the question that lying behavior is meant to inform, it may be necessary to evaluate lying time of the animals according to standards set for these factors. Especially for onfarm audits, targets for outcome-based measures need to take into account variation between animals. A 4-d sample accurately estimated daily lying time in tiestalls and freestalls taken over a 10 -d period. If reducing the sample period to $1 \mathrm{~d}$ may be suitable for on-farm audits, more research is needed for smaller farms to determine the accurate sample size so as not to significantly decrease the accuracy of lying time estimates.

\section{ACKNOWLEDGMENTS}

We thank Agriculture and Agri-Food Canada and the Dairy Farmers of Canada for financial support, provided through the Dairy Research Cluster initiative. We also thank Rémy Mainguy (École Supérieur d'Anger, Anger, France) and Émilie Turmeau (AgroCampus Rennes, Rennes, France) for data handling, Jessica Zaffino and Janet Higginson (both from University of Guelph, Guelph, ON, Canada), Jean-Philippe Parent, Marianne Villettaz-Robichaud, and Jason Beukens (all from Agriculture and Agri-Food Canada, Agassiz, BC, Canada) for technical assistance. We thank Nelson Dinn and staff of the University of British Columbia's dairy research center (Agassiz, BC, Canada) as well as Joe Parkinson and Laura Wright of the University of Guelph's dairy research center (Elora, ON, Canada).

\section{REFERENCES}

Chapinal, N., A. M. de Passillé, and J. Rushen. 2010a. Correlated changes in behavioral indicators of lameness in dairy cows following hoof trimming. J. Dairy Sci. 93:5758-5763.

Chapinal, N., A. M. de Passillé, J. Rushen, and S. Wagner. 2010b. Automated methods for detecting lameness and measuring analgesia in dairy cattle. J. Dairy Sci. 93:2007-2013.

Chapinal, N., A. M. de Passillé, D. M. Weary, M. A. G. von Keyserlingk, and J. Rushen. 2009. Using gait score, walking speed, and lying behavior to detect hoof lesions in dairy cows. J. Dairy Sci 92:4365-4374.

Chaplin, S., and L. Munksgaard. 2001. Evaluation of a simple method for assessment of rising behaviour in tethered dairy cows. Anim. Sci. 72:191-197.

DeVries, T. J., K. A. Beauchemin, F. Dohme, and K. S. SchwartzkopfGenswein. 2009. Repeated ruminal acidosis challenges in lactating dairy cows at high and low risk for developing acidosis: Feeding, ruminating, and lying behavior. J. Dairy Sci. 92:5067-5078.

DeVries, T. J., M. A. G. von Keyserlingk, D. M. Weary, and K. A. Beauchemin. 2003. Measuring the feeding behavior of lactating dairy cows in early to peak lactation. J. Dairy Sci. 86:3354-3361.

Endres, M. I., and A. E. Barberg. 2007. Behavior of dairy cows in an alternative bedded-pack housing system. J. Dairy Sci. 90:41924200 .

Fisher, A. D., G. A. Verkerk, C. J. Morrow, and L. R. Matthews 2002. The effects of feed restriction and lying deprivation on pituitary-adrenal axis regulation in lactating cows. Livest. Prod. Sci. $73: 255-263$.

Fregonesi, J. A., and J. D. Leaver. 2001. Behaviour, performance and health indicators of welfare for dairy cows housed in strawyard or cubicle systems. Livest. Prod. Sci. 68:205-216.

Fregonesi, J. A., and J. D. Leaver. 2002. Influence of space allowance and milk yield level on behaviour, performance and health of dairy cows housed in strawyard and cubicle systems. Livest. Prod. Sci. $78: 245-257$.

Fregonesi, J. A., D. M. Veira, M. A. G. Von Keyserlingk, and D. M. Weary. 2007. Effects of bedding quality on lying behavior of dairy cows. J. Dairy Sci. 90:5468-5472.

Gleeson, D. E., B. O'Brien, L. Boyle, and B. Earley. 2007. Effect of milking frequency and nutritional level on aspects of the health and welfare of dairy cows. Animal 1:125-132.

Haley, D. B., A. M. de Passillé, and J. Rushen. 2001. Assessing cow comfort: Effects of two floor types and two tie stall designs on the behaviour of lactating dairy cows. Appl. Anim. Behav. Sci. $71: 105-117$.

Haley, D. B., J. Rushen, and A. M. De Passillé. 2000. Behavioural indicators of cow comfort: Activity and resting behaviour of dairy cows in two types of housing. Can. J. Anim. Sci. 80:257-263.

Higginson, J. H., S. T. Millman, K. E. Leslie, and D. F. Kelton. 2010 Validation of a new pedometry system for use in behavioural research and lameness detection in dairy cattle. Proc. First North Am. Conf. Precision Dairy Management, Toronto, ON, Canada. Progressive Dairy Operators, Elora, ON, Canada.

Ito, K., D. M. Weary, and M. A. G. von Keyserlingk. 2009. Lying behavior: Assessing within- and between-herd variation in freestallhoused dairy cows. J. Dairy Sci. 92:4412-4420.

Jensen, M. B., L. J. Pedersen, and L. Munksgaard. 2005. The effect of reward duration on demand functions for rest in dairy heifers and lying requirements as measured by demand functions. Appl. Anim. Behav. Sci. 90:207-217.

Knierim, U., and C. Winckler. 2009. On-farm welfare assessment in cattle: Validity, reliability and feasibility issues and future perspectives with special regard to the Welfare Quality approach. Anim. Welf. 18:451-458.

Munksgaard, L., and P. Løvendahl. 1993. Effects of social and physical stressors on growth hormone levels in dairy cows. Can. J. Anim. Sci. $73: 847-853$.

Munksgaard, L., and H. B. Simonsen. 1996. Behavioral and pituitary adrenal-axis responses of dairy cows to social isolation and deprivation of lying down. J. Anim. Sci. 74:769-778.

Nielsen, B. L., R. F. Veerkamp, and A. B. Lawrence. 2000. Effects of genotype, feed type and lactational stage on the time budget of dairy cows. Acta Agric. Scand. A 50:272-278.

Norring, M., A. Valros, and L. Munksgaard. 2011. Milk yield affects time budget in dairy cows kept in tie-stalls. Article from $\mathrm{PhD}$ thesis: The effects of stall surfaces and milk yield on the lying behavior of dairy cow, Faculty of Veterinary Medicine, University of Helsinki, Finland.

NRC. 2001. Nutrient Requirements of Dairy Cattle. 7th rev. ed. National Academy Press, Washington, DC. 
O'Driscoll, K., L. Boyle, and A. Hanlon. 2008. A brief note on the validation of a system for recording lying behaviour in dairy cows. Appl. Anim. Behav. Sci. 111:195-200.

O'Driscoll, K., D. Gleeson, B. O'Brien, and L. Boyle. 2011. Does omission of a regular milking event affect cow comfort? Livest. Sci. 138:132-143.

Olmos, G., L. Boyle, A. Hanlon, J. Patton, J. J. Murphy, and J. F. Mee. 2009. Hoof disorders, locomotion ability and lying times of cubicle-housed compared to pasture-based dairy cows. Livest. Sci. 125:199-207.

Proudfoot, K. L., D. M. Weary, and M. A. G. von Keyserlingk. 2010. Behavior during transition differs for cows diagnosed with claw horn lesions in mid lactation. J. Dairy Sci. 93:3970-3978.

Rushen, J., A. Butterworth, and J. C. Swanson. 2011. Animal Behavior and Well-Being Symposium: Farm animal welfare assurance: Science and application. J. Anim. Sci. 89:1219-1228.

Rushen, J., A. M. de Passillé, M. A. G. von Keyserlingk, and D. M. Weary. 2008. The Welfare of Cattle. Springer, Dordrecht, the Netherlands.
Rushen, J., D. Haley, and A. M. de Passillé. 2007. Effect of softer flooring in tie stalls on resting behavior and leg injuries of lactating cows. J. Dairy Sci. 90:3647-3651.

Singh, S. S., W. R. Ward, K. Lautenbach, J. W. Hughes, and R. D. Murray. 1993. Behaviour of first lactation and adult dairy cows while housed and at pasture and its relationship with sole lesions. Vet. Rec. 133:469-474.

Tucker, C. B., D. M. Weary, M. A. G. von Keyserlingk, and K. A. Beauchemin. 2009. Cow comfort in tie-stalls: Increased depth of shavings or straw bedding increases lying time. J. Dairy Sci. 92:2684-2690.

von Keyserlingk, M. A. G., K. L. Proudfoot, L. Vickers, and D. M. Weary. 2011. Using cow behaviour to predict disease. Adv. Dairy Technol. 23:61-69; Proc. Western Canadian Dairy Seminar. University of Alberta, Edmonton, AB, Canada.

Wittrock, J. M., K. L. Proudfoot, D. M. Weary, and M. A. G. von Keyserlingk. 2011. Short communication: Metritis affects milk production and cull rate of Holstein multiparous and primiparous dairy cows differently. J. Dairy Sci. 94:2408-2412. 